\title{
Unraveling the Nature of Active Sites in Ethanol Electro- oxidation by Site-Specific Marking of a Pt Catalyst with Isotope-Labeled ${ }^{13} \mathrm{CO}$
}

\author{
Manuel J. S. Farias*,†, William Cheuquepán ${ }^{\ddagger}$, Auro A. Tanaka ${ }^{\dagger}$, and Juan M. Feliu ${ }^{\ddagger}$ \\ ${ }^{\dagger}$ Departamento de Química, Universidade Federal do Maranhão, Avenida dos \\ Portugueses, 1966, CEP 65080-805, São Luís - Maranhão, Brazil \\ ${ }^{\ddagger}$ Instituto de Electroquímica, Universidad de Alicante Ap. 99, E-03080, Alicante, Spain
}

\begin{abstract}
:
This works deals with the identification of preferential site-specific activation at a model Pt surface during a multiproduct reaction. The (110)-type steps of a $\operatorname{Pt}(332)$ surface were selectively marked by attaching isotope-labeled ${ }^{13} \mathrm{CO}$ molecules to them, and ethanol oxidation was probed by in situ Fourier transform infrared spectroscopy in order to precisely determine the specific sites at which $\mathrm{CO}_{2}$, acetic acid, and acetaldehyde were preferentially formed. The (110) steps were active for splitting the $\mathrm{C}-\mathrm{C}$ bond but unexpectedly, we provide evidence that the pathway of $\mathrm{CO}_{2}$ formation was preferentially activated at (111) terraces, rather than at (110) steps. Acetaldehyde was formed at (111) terraces at potentials comparable to those for $\mathrm{CO}_{2}$ formation also at (111) terraces, while the acetic acid formation pathway only became active when the (110) steps were released by the oxidation of adsorbed ${ }^{13} \mathrm{CO}$, at potentials higher than for the formation of $\mathrm{CO}_{2}$ at (111) terraces of the stepped surface.
\end{abstract}




\section{Graphical Abstract}

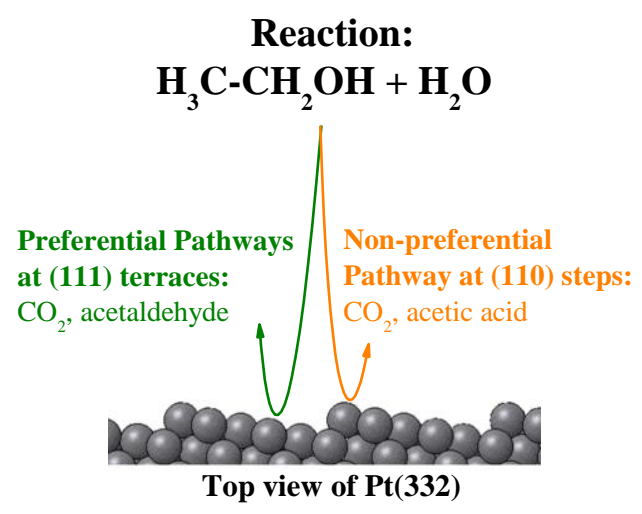

Description of the relationships between reaction activation pathways and specific sites at solid surfaces is a demanding task that is necessary for improving understanding of the chemistry of heterogeneous (electro)catalysis at the molecular level. As early as 1925, Taylor ${ }^{1}$ pointed out that real solid catalysts possess non-equivalent sites, which today are characterized as steps/defects, close-packed domains, ad-atoms, holes, and so on. ${ }^{2}$ These different local surface crystallographic orientations are surrounded by different chemical environments and can vary in activity along the catalyst surface. ${ }^{3}$ Consequently, the catalytic activity at the macroscopic scale results from the contributions of sites with different activities. This means that the identification of specific sites in multi-product reactions becomes more challenging, because in the mechanisms of these reactions, different reaction pathways may compete for the same active sites, with the various catalytic activities affecting the overall reaction rate.

Information on the identity of active sites is essential for understanding the nature of factors limiting the efficiency of a catalyst. ${ }^{4}$ This is a key issue in energy conversion technology, as in the case of the electrocatalytic oxidation of ethanol, a convenient candidate for use in low temperature fuel cells. The use of infrared spectroelectrochemistry techniques to monitor the products of ethanol electro-oxidation at a $\mathrm{Pt}$ single crystal ${ }^{5}$ revealed that it is a surface structure-sensitive reaction. From the catalytic viewpoint, one challenge in ethanol electro-oxidation is that almost all catalysts leave the $\mathrm{C}-\mathrm{C}$ bond intact, ${ }^{6,7}$ resulting in reaction products such as acetic acid or acetaldehyde that are associated with lower exploitation of the ethanol energy capacity. So, from the energy conversion perspective, it is desirable to tune the reaction pathway toward $\mathrm{CO}_{2}$, and 
beyond this, as a fundamental scientific question, it is important to understand the factors that favor or hinder it. The pathway to $\mathrm{CO}_{2}$ requires cleavage of the $\mathrm{C}-\mathrm{C}$ bond, with this reaction step being more favorable at step/defect sites than at (111) planes. ${ }^{8,9}$ Therefore, steps/defects have been proposed to be the only active sites for the formation of $\mathrm{CO}_{2}$ during ethanol oxidation, ${ }^{8,10}$ while the pathway towards acetic acid has been suggested to be highly active on the (111) planes. ${ }^{11}$ Additionally, insight into the reaction mechanism of ethanol oxidation has been achieved using isotope-labeled ethanol, evidencing the existence of preferential routes in ethanol dissociation/oxidation. ${ }^{12-14}$ However, it is important to note that in previous work, there has been no control over the identity of the active sites and their relationships with specific reaction products or with the activation of the reaction pathway. An elegant methodology to identify active sites involves the selective blocking/marking of sites, but this is not a simple task, because the species used to block/mark active sites may affect the chemistry (reactivity, catalytic activity, etc.) of neighboring sites, as occurs with ad-atoms blocking sites. ${ }^{15}$ Ideally, a neutral blocking/marking species should be employed, such as a "marked" reaction intermediate. Here, we overcome that difficulty by selectively marking the (110)-type steps of a stepped (111) Pt surface using isotope-labeled ${ }^{13} \mathrm{CO}$, followed by examination of the activities of the remaining sites towards different reaction products coming from the ethanol electrooxidation. In the course of ethanol electro-oxidation, $\mathrm{CO}_{\mathrm{ads}}$ appears as a reaction intermediate, ${ }^{5}$ so the ${ }^{13} \mathrm{CO}_{\text {ads }}$ deliberately attached at the (110) steps acts as both a sitespecific species marker and a neutral/natural intermediate in the $\mathrm{CO}_{2}$ pathway.

A well characterized $\operatorname{Pt}(332)$ stepped surface was employed, consisting of a 5-atom wide (111) terrace, periodically interrupted by monoatomic (110) steps, as shown in the hard sphere model in Figure 1, where the structure corresponding to (110) monoatomic steps is represented by a square, while the structure corresponding to the (111) terraces is 
represented by a hexagon. The $\mathrm{Pt}(332)$ crystal was prepared as described previously. ${ }^{16}$ The selection of this surface was based on its easier CO step sites decoration and its terraces width that was neither too short nor too long. The experimental details are provided in the Supporting Information.

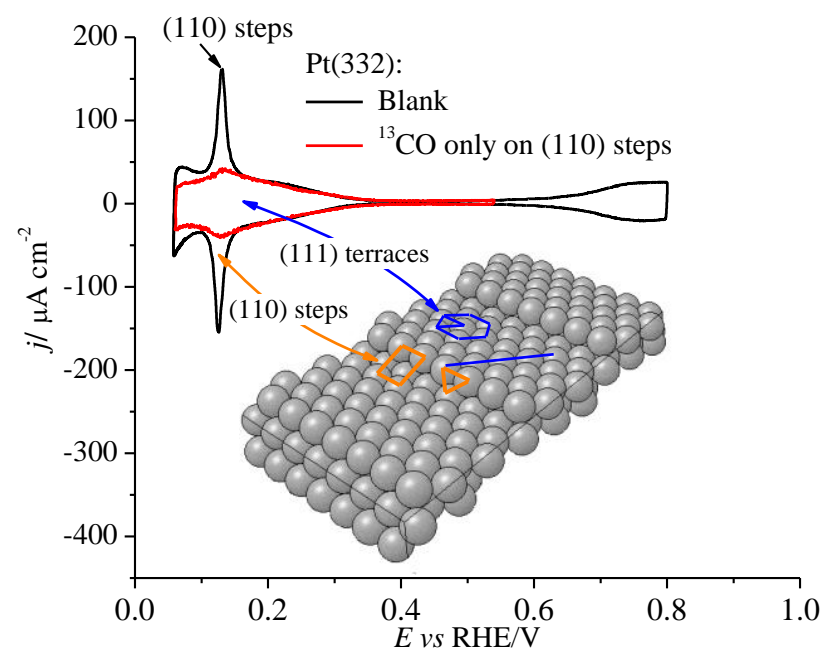

Figure 1. Cyclic voltammograms of $\operatorname{Pt}(332)$ in $0.1 \mathrm{M} \mathrm{HClO}_{4}$, obtained at $50 \mathrm{mV} \mathrm{s}^{-1}$. Black line: blank; red line: ${ }^{13} \mathrm{CO}$ only on (110) steps. The data include a hard sphere model of $\operatorname{Pt}(332)$.

Figure 1 shows the cyclic voltammogram of $\mathrm{Pt}(332)$ in $0.1 \mathrm{M} \mathrm{HClO}_{4}$ (black line) and the voltammogram obtained when the ${ }^{13} \mathrm{C}^{16} \mathrm{O}$ (henceforth denoted ${ }^{13} \mathrm{CO}$ ) was selectively attached at the (110) steps (red line). The protocol used to obtain ${ }^{13} \mathrm{CO}$ only on the (110) steps consisted of voltammetric partial oxidation of a full ${ }^{13} \mathrm{CO}$ adlayer. Briefly, a full adlayer of ${ }^{13} \mathrm{CO}$ was prepared at the electrode, after which the $\mathrm{CO}$ adlayer was oxidized by applying several voltammetric cycles, limiting the upper potential in order to avoid oxidation of the entire ${ }^{13} \mathrm{CO}$ adlayer at once. The oxidation of the $\mathrm{CO}$ adlayer at the (111) stepped Pt surface consisting of (110) steps preferentially occurred at the (111) terraces, with the CO oxidation at (110) steps only starting after all the $\mathrm{CO}$ at the (111) terraces had been oxidized. Then, since the $\mathrm{CO}_{\text {ads }}$ in the remaining layer behaved as an immobile species during its oxidation, ${ }^{17}$ it was possible to acquire ${ }^{13} \mathrm{CO}$ in the residual ${ }^{13} \mathrm{CO}$ layer 
only at the row of (110) steps. In Figure 1, the reversible peaks at $\sim 0.128 \mathrm{~V}$ (black line) correspond to hydrogen adsorption/desorption at (110) steps. For the experiment with ${ }^{13} \mathrm{CO}$ only on (110) steps, only these features were suppressed in the hydrogen region. All the features below these processes at $\sim 0.128 \mathrm{~V}$ corresponded to hydrogen adsorption/desorption at the (111) terraces. In Figure 1, all these sites were fully freed of ${ }^{13} \mathrm{CO}_{\mathrm{ads}}$, as shown by comparison of the red line with the black line.

A typical voltammetric profile of $10 \mathrm{mM}$ ethanol oxidation on a stepped Pt surface is presented in Figure 2 (red line), together with a blank voltammogram (black line). The (110) steps were indicative of low adsorption of ethanol at that concentration. All the (111) terraces remained completely unaltered, showing that the (111) terraces were less active for ethanol adsorption/dissociation than the steps, at least at low potentials. The protagonist action of the (111) terraces in ethanol oxidation was evidenced by the experiments shown in Figure 2, which compares voltammograms for ethanol oxidation at bare $\operatorname{Pt}(332)$ (red line) and $\operatorname{Pt}(332)$ with $\mathrm{CO}_{\text {ads }}$ selectively attached at the (110) steps (blue line). In order to carry out these experiments, after the preparation of (110) steps decorated with $\mathrm{CO}$ (normal $\mathrm{CO}$ ), the electrode was polarized at $0.100 \mathrm{~V}$ and an aliquot of ethanol was added directly into the electrochemical cell, to a concentration of $10 \mathrm{mM}$. In order to analyze the data in Figure 2, it is opportune to mention that by using stripping voltammetry, in acid media the CO oxidation at the (110) steps of a stepped Pt single crystal with (111) terraces only develops maximum activity at $\sim 0.72 \mathrm{~V} .{ }^{17}$ In Figure 2 (blue line), all the (110) steps were previously fully blocked by $\mathrm{CO}_{\text {ads, }}$, so the only sites available to participate in the ethanol oxidation/dissociation were the (111) terraces. However, it can be seen that in the presence (blue line) and absence (red line) of CO previously attached at the steps, the voltammograms were virtually identical between $\sim 0.2$ and $\sim 0.5 \mathrm{~V}$. This similarity suggested a predominant participation of (111) terraces in the 
overall current density for ethanol oxidation at potentials above $\sim 0.35 \mathrm{~V}$, especially if it is considered that at potentials lower than $\sim 0.72 \mathrm{~V}$, the (110) steps were blocked by $\mathrm{CO}_{\text {ads. }}{ }^{17}$ The molecular factors controlling this behavior are elucidated in Figures 3-4.

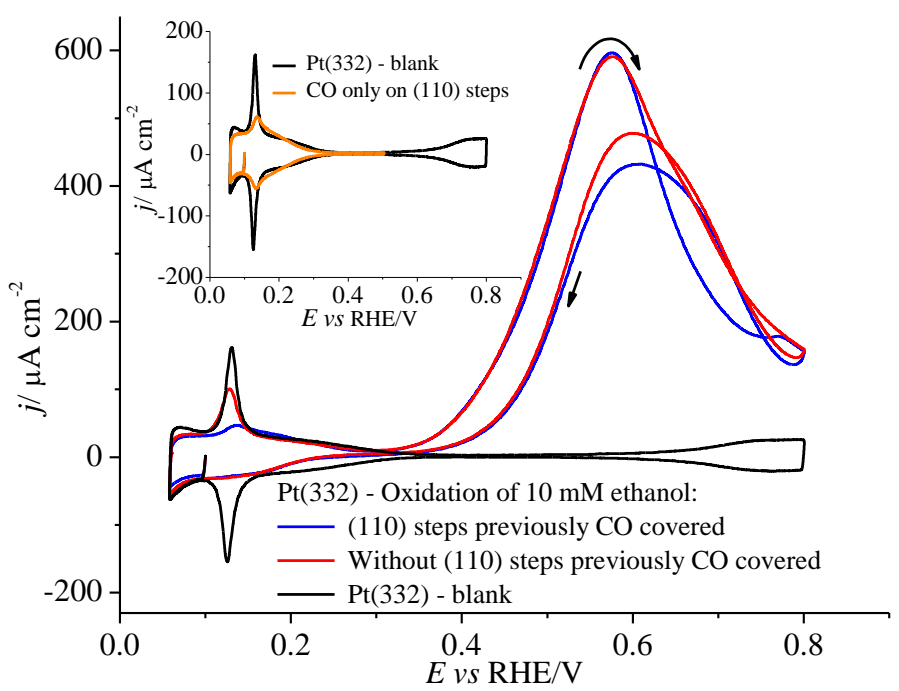

Figure 2. Ethanol (10 mM) electro-oxidation at $\operatorname{Pt}(332)$ in $0.1 \mathrm{M} \mathrm{HClO}_{4}$, at $50 \mathrm{mV} \mathrm{s}^{-1}$, in the presence (blue line) and absence (red line) of $\mathrm{CO}_{\text {ads }}$ previously deposited at the (110) steps. Inset: voltammograms for the blank (black line) and for (110) steps decorated with $\mathrm{CO}$ (orange line).

The acquisition of in situ FTIR spectra (Figure 3) employed the following experimental protocol. Firstly, the $\operatorname{Pt}(332)$ electrode in the FTIR cell was fully covered with isotope-labeled ${ }^{13} \mathrm{CO}$ by bubbling ${ }^{13} \mathrm{CO}$ gas into the cell for $5 \mathrm{~min}$, followed by purging the solution with Ar for 25 min. A partial ${ }^{13} \mathrm{CO}$ stripping experiment was then performed, in which ${ }^{13} \mathrm{CO}$ only remained at the (110) steps. In the experiment of Figure 3 , the decorated ${ }^{13} \mathrm{CO}$ surface is that shown in Figure 1 (red line). Then, an aliquot of ethanol was added directly into the solution, to a concentration of $10 \mathrm{mM}$, while maintaining the potential at $0.100 \mathrm{~V}$. The electrode was pressed against the prismatic optical window $\left(\mathrm{CaF}_{2}\right)$ to record in situ spectra (200 interferograms and resolution of 8 $\mathrm{cm}^{-1}$ ) from 0.100 to $0.800 \mathrm{~V}$, in intervals of $25 \mathrm{mV}$. Here, the series of spectra are shown for potentials above $0.400 \mathrm{~V}$. 


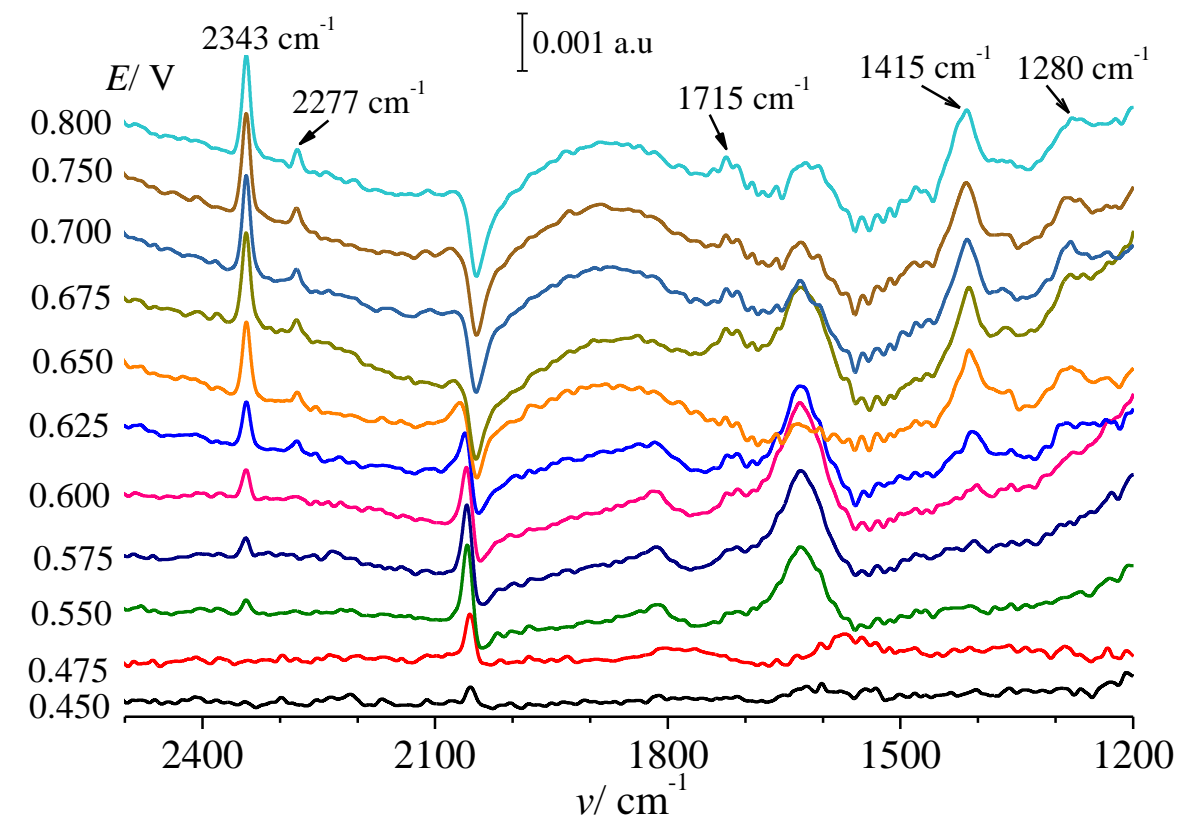

Figure 3. Spectra for ethanol $(10 \mathrm{mM})$ electro-oxidation at $\mathrm{Pt}(332)$ with the (110) steps selectively decorated with ${ }^{13} \mathrm{CO}$. The reference spectrum was recorded at $0.400 \mathrm{~V}$.

Two $\mathrm{CO}_{2}$ band frequencies can be seen in Figure 3, one at $2343 \mathrm{~cm}^{-1}$, due to the $\mathrm{CO}_{2}$ coming from the oxidation of $\mathrm{CO}_{\text {ads }}$ derived from ethanol dissociation, and another at $2277 \mathrm{~cm}^{-1}$, due to the ${ }^{13} \mathrm{CO}_{2}$ coming from the oxidation of ${ }^{13} \mathrm{CO}$ that was previously attached at the (110) step sites. The band at $2343 \mathrm{~cm}^{-1}$ appeared at a lower potential $(\sim 0.500 \mathrm{~V})$ than the potential at which the band at $2277 \mathrm{~cm}^{-1}$ appeared $(\sim 0.625 \mathrm{~V})$. This enabled precise discrimination of the preferences for the activation pathways of $\mathrm{CO}_{2}$ formation at two different active sites, which were the (110) step sites (where the ${ }^{13} \mathrm{CO}_{2}$ was formed) and the (111) terrace sites (where the normal $\mathrm{CO}_{2}$ was formed) at the same catalyst surface containing these non-equivalent sites. Another important band appeared at $\sim 1280 \mathrm{~cm}^{-1}$, attributed to the combined $\mathrm{C}-\mathrm{O}$ stretching and $\mathrm{OH}$ deformation of the $\mathrm{COOH}$ group of acetic acid. ${ }^{18}$ This band appeared at $\sim 0.625 \mathrm{~V}$, the same potential at which the oxidation of ${ }^{13} \mathrm{CO}_{\text {ads }}$ at the (110) steps started. This suggested that the activation pathway of $\mathrm{CO}_{2}$ formation at the step sites and the acetic acid activation pathway were not independent. In previous experiments, acetic acid was always detected at potentials 
after the start of the $\mathrm{CO}_{2}$ activation pathway, ${ }^{9}$ but the reasons for this behavior will be clarified in this work. The band at $1415 \mathrm{~cm}^{-1}$, which appeared at $\sim 0.625 \mathrm{~V}$, was attributed to symmetric $\mathrm{O}-\mathrm{C}-\mathrm{O}$ stretching of the $\mathrm{COO}^{-}$group. The band at $\sim 1715 \mathrm{~cm}^{-1}$ corresponded to $\mathrm{C}=\mathrm{O}$ stretching of acetaldehyde or acetic acid ( $\mathrm{CHO}$ or $\mathrm{COOH}$ groups). ${ }^{11}$ Since the band at $\sim 1715 \mathrm{~cm}^{-1}$ appeared at $\sim 0.575 \mathrm{~V}$, before the acetic acid band at $\sim 1280 \mathrm{~cm}^{-1}$, it is reasonable to suppose that the acetaldehyde formation pathway was activated even when all the (110) steps were fully blocked with ${ }^{13} \mathrm{CO}$, which is consistent with the activation pathway of acetaldehyde formation at the (111) terrace sites of the stepped Pt surface. Bands at $\sim 2030 \mathrm{~cm}^{-1}$ and $\sim 2070 \mathrm{~cm}^{-1}$ were due to the stretching frequencies of linearly bonded $\mathrm{CO}$ at the (111) terraces. The spectra showed dominance of the ${ }^{12} \mathrm{CO}$ band over the ${ }^{13} \mathrm{CO}$ band, with the latter not being detected in the spectra. The spectra for the ${ }^{13} \mathrm{CO} /{ }^{12} \mathrm{CO}$ mixture evidenced the predominance of dipole-dipole coupling at the $\mathrm{CO}$ adlayer, ${ }^{19}$ with the intensity of the higher ${ }^{12} \mathrm{CO}_{\text {ads }}$ band frequency being reinforced at the expense of the ${ }^{13} \mathrm{CO}_{\text {ads }}$ band. ${ }^{20,21}$ This might explain the absence of the ${ }^{13} \mathrm{CO}$ ads band in Figure 3. Moreover, using a $\operatorname{Pt}(533) \equiv \operatorname{Pt}(s)-[4(111) \times(100)]^{22}$ surface and different proportions of ${ }^{13} \mathrm{CO} /{ }^{12} \mathrm{CO}$, due to the phenomena of transfer intensity, ${ }^{20,21}$ the band intensity related to ${ }^{13} \mathrm{CO}_{\text {ads }}$ at steps gradually decreased as the $\mathrm{CO}$ coverage at (111) terraces increased. ${ }^{22}$ Figure $\mathrm{S} 3$ shows spectra for the ${ }^{13} \mathrm{CO} /{ }^{12} \mathrm{CO}$ mixture. In the spectra shown in Figure 3, the bending mode of water appeared at $\sim 1600 \mathrm{~cm}^{-1}$.

Similarly for $100 \mathrm{mM}$ ethanol (Figure 4), all the (110) steps were selectively decorated with ${ }^{13} \mathrm{CO}$. It can be seen that the spectra exhibited trends similar to those in Figure 3, but with higher band intensities at $2343 \mathrm{~cm}^{-1}$, due to the $\mathrm{CO}_{2}$ from ethanol oxidation, and at around $\sim 1280 \mathrm{~cm}^{-1}$ and $1415 \mathrm{~cm}^{-1}$, because the generation of products was higher. 


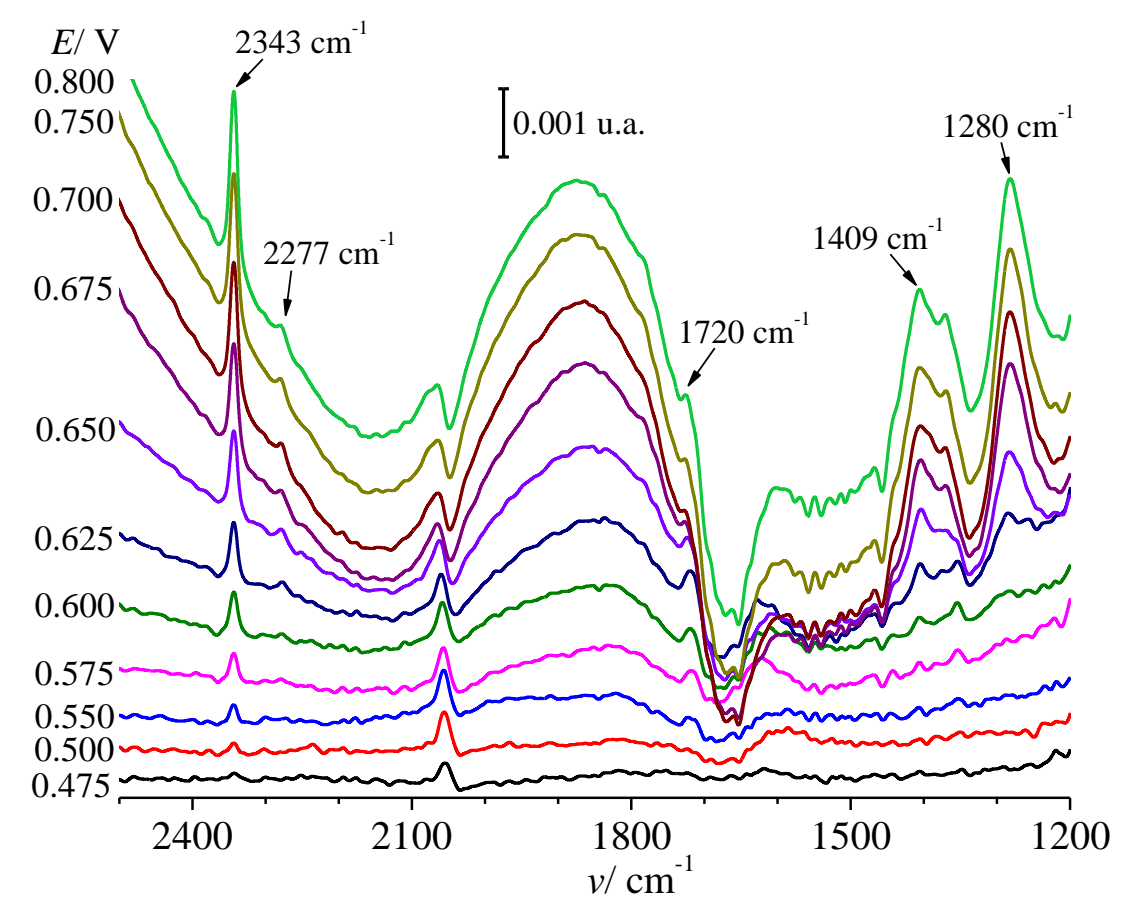

Figure 4. Spectra for $100 \mathrm{mM}$ ethanol electro-oxidation at $\mathrm{Pt}(332)$ with the (110) steps selectively decorated with ${ }^{13} \mathrm{CO}$. The reference spectrum was recorded at $0.400 \mathrm{~V}$.

As described in the literature, ${ }^{8-10}$ compared to the (111) terraces, the experiments confirmed that the (110) step sites were more capable of catalyzing cleavage of the C-C bond of the ethanol molecule at low potentials, and calculations suggest that breaking of the $\mathrm{C}-\mathrm{C}$ bond requires a substantial ensemble of atoms on the surface. ${ }^{23}$ Concerning sitespecificity, the results revealed other properties of the step sites in ethanol oxidation and the protagonist role of (111) terraces at low potentials. The in situ FTIR spectra (Figures 3-4) showed that although the (111) terraces provided only weak C-C bond cleavage, these sites were much more effective in the activation pathway for $\mathrm{CO}_{2}$ formation at low potential $(\sim 0.525 \mathrm{~V})$, compared to the catalytic activity of the (110) step sites (where $\mathrm{CO}_{2}$ formation started at $\sim 0.625 \mathrm{~V}$ ). This discrimination of the catalytic activities of nonequivalent sites toward the same reaction product $\left(\mathrm{CO}_{2}\right)$ was successfully revealed by the experimental strategy of chemically marking the (110) step sites by attachment of ${ }^{13} \mathrm{CO}$ from the gas phase. This procedure precisely mirrored the attachment of a natural reaction 
intermediate at selected active sites (the (110) steps at a $\operatorname{Pt}(332)$ stepped surface), leaving all the other sites characterized as (111) terraces free for evaluation of their catalytic properties during ethanol oxidation. According to the spectra shown in Figures 3-4, the pathway to acetaldehyde formation was activated even when all the (110) steps were fully blocked with ${ }^{13} \mathrm{CO}$, meaning that acetaldehyde was formed at (111) terraces at potentials below $\sim 0.62 \mathrm{~V}$.

The unexpected higher catalytic activity for $\mathrm{CO}_{2}$ formation at (111) terraces could not be attributed specifically to the terraces themselves. It was previously observed that $\mathrm{CO}_{2}$ generation at "infinite" (111) planes was low and only occurred above $\sim 0.7$ VRHE. ${ }^{11}$ In the present case, $\mathrm{CO}_{2}$ formation at (111) terraces was observed at $\sim 0.525 \mathrm{~V}$, implying that the catalytic properties of "infinite" (111) plane surfaces differed greatly from those at stepped surfaces of the (111) plane. It is likely that the properties of the (111) terraces were modified by the steps, due to the Smoluchwski effect. ${ }^{24}$ This involves the charge distribution at the steps, with a lack of it at the top side and accumulation of it at the bottom side, as a surface dipole. The steps probably modified the catalytic properties of the (111) terraces, making them the most favorable locations for activation of the $\mathrm{CO}_{\text {ads }}$ oxidation pathway. Therefore, although the steps were most effective in cleaving the C$\mathrm{C}$ bond to form $\mathrm{CO}_{\text {ads }}$, their ability to convert $\mathrm{CO}_{\text {ads }}$ to $\mathrm{CO}_{2}$ was lower, compared to the (111) terraces at the stepped Pt surface. Hence, if $\mathrm{CO}_{\text {ads }}$ is conceived as a catalytic poison, its adsorption at steps had a greater catalyst poisoning effect than at the (111) flat structure. This easier conversion of $\mathrm{CO}_{\text {ads }}$ to $\mathrm{CO}_{2}$ at (111) terraces probably involved the carbon of the alcoholic group, which is more reactive than the ethyl group. ${ }^{25}$

Comparison of the potentials for $\mathrm{CO}_{2}$ formation at the (111) terraces (Figures 3-4) showed that $\mathrm{CO}_{2}$ formation unequivocally preceded the appearance of acetic acid. From a mechanistic perspective, both $\mathrm{CO}_{2}$ and acetic acid formation require the transfer of one external oxygen atom derived from a water molecule. According to the thermodynamics 
(Table 1), the acetic acid pathway presents a standard potential $E^{0} \simeq 0.058 \mathrm{~V}_{\text {SHE}}$, while for the $\mathrm{CO}_{2}$ pathway $E^{0} \simeq 0.085 \mathrm{~V}_{\text {SHE }}$, and for acetaldehyde $E^{0} \simeq 0.246 \mathrm{~V}_{\text {SHE }}$.

Table 1. Standard Potentials ${ }^{a}\left(E^{0} / \mathrm{V}_{\mathrm{SHE}}\right)$ and the Number of Exchanged Electrons $\left(n_{\mathrm{e}-}\right)$ for the Electrochemical Oxidation of Ethanol.

\begin{tabular}{lcc}
\hline electrochemical reaction & $\boldsymbol{E}^{\mathbf{0}}$ & $n_{e^{-}}$ \\
\hline $\mathrm{H}_{3} \mathrm{C}-\mathrm{CH}_{2} \mathrm{OH}_{(l)}+3 \mathrm{H}_{2} \mathrm{O}_{(l)} \rightleftarrows 2 \mathrm{CO}_{2(g)}+12 \mathrm{H}^{+}+12 e^{-}$ & 0.085 & 12 \\
$\mathrm{H}_{3} \mathrm{C}-\mathrm{CH}_{2} \mathrm{OH}_{(l)}+\mathrm{H}_{2} \mathrm{O}_{(l)} \rightleftarrows \mathrm{H}_{3} \mathrm{C}-\mathrm{COOH}_{(l)}+4 \mathrm{H}^{+}+4 e^{-}$ & 0.058 & 4 \\
$\mathrm{H}_{3} \mathrm{C}-\mathrm{CH}_{2} \mathrm{OH}_{(l)} \rightleftarrows \mathrm{H}_{3} \mathrm{C}-\mathrm{CHO}(l)+2 \mathrm{H}^{+}+2 e^{-}$ & 0.246 & 2 \\
\hline${ }^{a}$ Calculated from standard thermodynamic data. ${ }^{26}$ & &
\end{tabular}

Based on the expected standard potentials, the pathways to acetic acid and $\mathrm{CO}_{2}$ were almost equally preferable. However, the results showed that the acetic acid pathway was accidentally hindered by $\mathrm{CO}_{\text {ads }}$ poisoning at the steps. At low potentials $(E<0.6 \mathrm{~V})$, acetic acid formation apparently did not occur at the (111) plane of stepped Pt surfaces, and only started when the steps were freed. The steps acted to change the mechanism of acetic acid formation at the (111) plane, which was not favored (at low potentials) at the (111) planes of the stepped surface.

In conclusion, we show that the protagonist effect of the (111) terraces is induced by the presence of steps. The step sites presented different functionalities at non-equivalent surface sites during the electrocatalysis of ethanol oxidation, modifying the activity of (111) terraces for the $\mathrm{CO}_{2}$ formation pathway at low potentials, and changing the mechanism of acetic acid formation. The preferential activation of the $\mathrm{CO}_{2}$ pathway at the (111) terraces indicated that these locations were most suitable for the transfer of external oxygen required for formation of $\mathrm{CO}_{2}$, rather than acetic acid at (110) steps or even at (111) terraces.

\section{Corresponding Author}

M.J.S.F.: e-mail, manueljsfarias@gmail.com

Tel: +559833018246.

\section{ACKNOWLEDGMENTS}


M.J.S.F. is grateful to PNPD/CAPES (Brazil). A.A.T acknowledges CAPES (PROCAD2013) and CNPq (309066/2013-1). J.M.F. thanks the MINECO (Spain) projectCTQ2013-44083-P.

\section{Supporting Information Available}

Additional experimental results, including the cyclic voltammetry and in situ FTIR data (PDF).

\section{REFERENCES}

(1) Taylor, H. S. A Theory of the Catalytic Surface. Proc. R. Soc. London. Ser. A 1925, 108, 105-111.

(2) Somorjai, G. A.; Li, Y. Introduction to Surface Chemistry and Catalysis; John Wiley \& Sons, Inc: New York, 2010.

(3) Buurmans, I. L. C.; Weckhuysen, B. M. Heterogeneities of Individual Catalyst Particles in Space and Time as Monitored by Spectroscopy. Nat. Chem. 2012, 4, 873-886.

(4) Somorjai, G. A.; Park, J. Y. Molecular Factors of Catalytic Selectivity. Angew. Chem. Int. Ed. 2008, 47, 9212-9228.

(5) Xia, X. H.; Liess, H. D.; Iwasita, T. Early Stages in the Oxidation of Ethanol at Low Index Single Crystal Platinum Electrodes. J. Electroanal. Chem. 1997, 437, 233-240.

(6) Wang, H.; Jusys, Z.; Behm, R. J. Ethanol Electrooxidation on a CarbonSupported Pt Catalyst: Reaction Kinetics and Product Yields. J. Phys. Chem. B 2004, 108, 19413-19424.

(7) Camara, G. A.; Iwasita, T. Parallel Pathways of Ethanol Oxidation: The Effect of Ethanol Concentration. J. Electroanal. Chem. 2005, 578, 315-321.

(8) Colmati, F.; Tremiliosi-Filho, G.; Gonzalez, E. R.; Berná, A.; Herrero, E.; Feliu, J. M. The Role of the Steps in the Cleavage of the C-C Bond During Ethanol Oxidation on Platinum Electrodes. Phys. Chem. Chem. Phys. 2009, 11, 9114-9123.

(9) Ferre-Vilaplana, A.; Buso-Rogero, C.; Feliu, J. M.; Herrero, E. Cleavage of the C-C Bond in the Ethanol Oxidation Reaction on Platinum. Insight from Experiments and Calculations. J. Phys. Chem. C 2016, 120, 11590-11597.

(10) Lai, S. C. S.; Koper, M. T. M. The Influence of Surface Structure on Selectivity in the Ethanol Electro-oxidation Reaction on Platinum. J. Phys. Chem. Lett. 2010, $1,1122-1125$.

(11) Colmati, F.; Tremiliosi-Filho, G.; Gonzalez, E. R.; Berna, A.; Herrero, E.; Feliu, J. M. Surface Structure Effects on the Electrochemical Oxidation of Ethanol on Platinum Single Crystal Electrodes. Faraday Discuss. 2009, 140, 379-397.

(12) Farias, M. J. S.; Camara, G. A.; Tanaka, A. A. Electrooxidation of IsotopeLabeled Ethanol: A FTIRS Study. J. Solid State Electrochem. 2007, 11, 1465-1469.

(13) Souza-Garcia, J.; Herrero, E.; Feliu, J. M. Breaking the C-C Bond in the Ethanol Oxidation Reaction on Platinum Electrodes: Effect of Steps and Ruthenium Adatoms. ChemPhysChem 2010, 11, 1391-1394. 
(14) Kutz, R. B.; Braunschweig, B.; Mukherjee, P.; Behrens, R. L.; Dlott, D. D.; Wieckowski, A. Reaction Pathways of Ethanol Electrooxidation on Polycrystalline Platinum Catalysts in Acidic Electrolytes. J. Catal. 2011, 278, 181-188.

(15) Chen, Q.-S.; Berna, A.; Climent, V.; Sun, S.-G.; Feliu, J. M. Specific Reactivity of Step Sites towards CO Adsorption and Oxidation on Platinum Single Crystals Vicinal to Pt(111). Phys. Chem. Chem. Phys. 2010, 12, 11407-11416.

(16) Clavilier, J.; Faure, R.; Guinet, G.; Durand, R. Preparation of Monocrystalline Pt Microelectrodes and Electrochemical Study of the Plane Surfaces Cut in the Direction of the $\{111\}$ and $\{110\}$ Planes. J. Electroanal. Chem. 1980, 107, 205209.

(17) Farias, M. J. S.; Camara, G. A.; Feliu, J. M. Understanding the CO Preoxidation and the Intrinsic Catalytic Activity of Step Sites in Stepped Pt Surfaces in Acidic Medium. J. Phys. Chem. C 2015, 119, 20272-20282.

(18) Iwasita, T.; Nart, F. C. In situ Infrared Spectroscopy at Electrochemical Interfaces. Prog. Surf. Sci. 1997, 55, 271-340.

(19) Chang, S. C.; Weaver, M. J. Coverage-Dependent Dipole Coupling for Carbon Monoxide Adsorbed at Ordered Platinum(111)-Aqueous Interfaces: Structural and Electrochemical Implications. J. Chem. Phys. 1990, 92, 4582-4594.

(20) Persson, B. N. J.; Ryberg, R. Vibrational Interaction between Molecules Adsorbed on a Metal Surface: The Dipole-Dipole Interaction. Phys. Rev. B 1981, 24, 6954-6970.

(21) Severson, M. W.; Stuhlmann, C.; Villegas, I.; Weaver, M. J. DipoleDipole Coupling Effects upon Infrared Spectroscopy of Compressed Electrochemical Adlayers: Application to the Pt(111)/CO System. J. Chem. Phys. 1995, 103, 9832-9843.

(22) Kim, C. S.; Tornquist, W. J.; Korzeniewski, C. Site-Dependent Vibrational Coupling of CO Adsorbates on Well-Defined Step and Terrace Sites of Monocrystalline Platinum: Mixed-Isotope Studies at $\operatorname{Pt}(335)$ and $\mathrm{Pt}(111)$ in the Aqueous Electrochemical Environment. J. Chem. Phys. 1994, 101, 9112-9121.

(23) An, W.; Men, Y.; Wang, J.; Liu, P. Interfacial and Alloying Effects on Activation of Ethanol from First-Principles. J. Phys. Chem. C 2017, 121, 5603-5611.

(24) Smoluchowski, R. Anisotropy of the Electronic Work Function of Metals. Phys. Rev. 1941, 60, 661-674.

(25) Shin, J.; Tornquist, W. J.; Korzeniewski, C.; Hoaglund, C. S. Elementary Steps in the Oxidation and Dissociative Chemisorption of Ethanol on Smooth and Stepped Surface Planes of Platinum Electrodes. Surf. Sci. 1996, 364, 122-130.

(26) Lide, D. L. CRC Handbook of Chemistry and Physics; CRC Press, 87 ${ }^{\mathrm{TH}}$, 2006-2007. 